\title{
The Effect of Health Safety Management in National Development
}

\author{
Dennis 0. Ikeogu \\ Department of Agricultural Science Education \\ School of Agriculture and Home Economics \\ Federal College of Education (Technical), Umunze-Anambra State,Nigeria \\ Joseph 0. Uwakwe \\ Department of Health and Physical Education \\ School of Sciences \\ Federal College of Education (Technical), Umunze-Anambra State,Nigeria \\ Ifeyinwa B. Chidolue \\ Department of Home Economics Education \\ School of Agriculture and Home Economics \\ Federal College of Education (Technical), Umunze-Anambra State,Nigeria
}

\section{Doi:10.5901/mjss.2013.v4n7p93}

\section{Abstract}

The most important resources of any country are its human resources and no nation is stronger than its citizens. Basically, the efficiency, strength and capability of citizens is their freedom from emotional, physical, mental and social illnesses and from accidents or harm. Today, accidents and diseases constitute vital social and personal problems facing our country. Millions of people have lost their lives as a result of accidents (preventable and non-preventable) and millions suffer disabling injuries. It is noteworthy that diseases and accidents cause more death than any other factors. Most of this is due to lack of health and safety education/ management and as such, it is most essential that our youths and adults become familiar with the hazards and diseases of our modern day living and learn how to live safely within their environment. Such quality of health and safety based instruction and training does not result from mere chance, it must be cultivated from a desire to live most and serve best. Direction towards these ends is the purpose of this paper. The goal of health and safety education is to help students and the general public learns about healthy behaviours and safety skills which help to address common health and security issues through education and outreach to support healthy and safe living conditions. It is necessary that safety education be incorporated in health education so that children are taught safety practices early in life in order to enjoy quality health and practice safe.

\section{Introduction}

In safety and health, reactive response occurs after an injury or illness and usually has the purpose of minimizing the costs associated with the injury or illness. For example, when people treat illnesses or injury instead of prevent them, they are adopting a reactive approach to health and safety. When management emphasizes a reactive approach to safety and health, it sends a negative message to employees. Reactive programs always cost much more than proactive programs because reactive waits until an injury or illness has occurred. Reactive programs kick in only after an accident has occurred.

Examples of reactive safety programs include:

1. Accountability system that tie discipline to accidents. 


\section{Accident investigation to fix the blame.}

On the other hand, a proactive response to safety and health takes place before the occurrence of an accident or illness. It anticipates and tries to prevent accident. By emphasizing accident prevention, management sends a message of caring to both staff and students. This approach is less expensive in the long term as a result of fewer accidents and injuries. Some examples of proactive safety and health programs include:

1. Hazard analysis to fix the problems

2. Inspection of the system

3. Incentive/ recognition programs that recognize compliance, reporting, suggesting and involvement.

4. Establishment of safety committees and or safety teams.

Proactive approach to health and safety involves all activities directed towards the prevention of accident, the measures taken to manage risks, analyze hazards in the environment, prevent sicknesses or diseases and maintain a zero lost workday for staff and zero lost schooldays for students. Proactive approaches to health and safety education is not just meant for the school environment and industries but can benefit the entire community as it concerns maintaining quality life by ensuring protection from risks of life and prevention of diseases by taking proper care of ones life, property and environment by eating food free of germs, drinking clean water, engaging in environmental sanitation in order to obtain a disease and hazard free environment. Health and safety is an important aspect of educational program because it trains people on the acquisition of necessary health habits, safety skills and practices to ensure that the objective of this program is achieved. this course of study should be adopted by schools both primary, secondary and tertiary institutions so that children can learn at their youth age positive behaviours that will carry them throughout their life time and also engage in safe practices which will prevent them from unexpected danger in the home front, at school and any other environment they find themselves.

\section{Health Education\& Safety}

Health and safety management is a desirable objective which can be achieved through education. The term health education is a social science that is drawn from the biological, environmental, psychological, physical and medical sciences to promote health and prevent diseases, disability and premature death through education driver voluntary behaviour change activities. (Green and Creufer 2005)

Health Education defined as comprising or consciously constructed opportunities for learning involving some form of communication designed to improve health literacy, including improving knowledge and developing life skill which are conducive to individual and community health.

According to world health organization (WHO), Health Education is defined as any combination of leaning experiences designed to help individuals and communities improve their health by increasing their knowledge or influence their health knowledge. The front committee on Health Education and promotion terminology (2011), defined Health Education as any combination of planned learning experience based on sound theories that provide individuals, groups and communities the opportunity to acquire information and the skills needed to make quality health decisions. Okoye (1999) defined Health Education as the principle by which individuals and groups of people learn to behave in a manner conducive to the maintenance of health. The Encyclopedia of medical concepts defined it as Dowbice et al (1996) provides a broader context of health education in relation to policy, system of environmental changes in the practice of health promotion and related philosophies education that increases the awareness and favourably influences the attitudes and knowledge relating to the improvement of health on a personal or community basis.

From the above definitions, it can be deduced that Health Education is an educational programme designed to get people (individuals, groups and communities) acquainted with issues regarding their health and environment in order to bring about a change in health behaviours and attitudes for the promotion, 
maintenance and restoration of quality health. This goes to show that the ultimate aim of health education is positive behavoural modification.

Safety on the other hand in the state or condition of being protected against physical, social, spiritual, financial, political, emotional, occupational, psychological, educational or other types or consequences of failure, damage, error, accidents, harm or any other event which could be considered non-desirable. Akwue (2011), defined safety to be the control of recognized hazards to achieve an acceptable level of risk. This can take the form of being protected from the event or from exposure to something that causes health or economical houses. It can include protection of people or possessions.

Ajibola (2008) sees safety as a relative freedom from danger, risks, or threat of harm, injury or loss to personnel and property whether caused deliberately or by accident. Orji (1994) views safety as the ability to manage risks inherent to operations or related to the environment or the commitment to clear identification of risks in relation tom production operations, assessing them in terms of quality, quantity and managing them.

Thus, Safety therefore deals with identification or recognition of danger, risks and security threats pertaining to life and property and putting in place appropriate measures to prevent and control them.

Health and safety education's theory and practice base have broadened from focusing on one-to-one and mass media behavioral intervention to encompass responsibility for policies, system and environment that affect population health. In the $21^{\text {st }}$ century, health and safety education became considered as a mature profession given that it has developed a discrete body of knowledge, defined competencies, a certification system for individuals, a code of ethics, a federal classification and recognized accreditation processes in higher education. Health and safety management is generally aligned with the behavioural and social sciences as one of the core dimensions of public health study and practices. Additionally, the fields draw from theories and models from education, health studies, communications, and other diverse areas. The unique combinations of these knowledgeable areas formed the basis for health and safety education competencies.

Similarly, the need for safety education arose as a result of increase in death toll which is due to numerous accidents and hazards in all aspects of human life as well as the environment. Safety education became very popular in the $21^{\text {st }}$ century as awareness of occupational hazards and interest in worker's protection had increased in the public and private sector. Through assessments conducted, it was apparently clear that there was a shortage of qualified industrial health and safety specialists to meet the challenges of worker's health and safety in the economy. The Educational Resource Centers (ERCs) now called Educational and Research Centers to better reflects their dual roles were established to assist selected institutions to develop and expand existing occupational health and safety training programs and to provide continuing education courses for specialists currently practicing in the specified field. Therefore, Health and Safety education was designed to assist young ones and adults to be able to learn and adopt healthy and safe behaviours, provides guidance on health education and safety assessment, enduring understanding, essential health education skills and safety practices, functional knowledge on safety and health issues, health education skill instruction pedagogy.

Health and Safety education focuses around major areas such as assessing, planning, implementing, managing and evaluating health and safety educational management, its skill practices and interventions. It includes historical and philosophical foundations and development of this professionalism and ethics.

These disciplines embrace both qualitative and quantitative methods, community-based participatory research, health communication and social marketing principles, policy and media advocacy to accomplish program objectives.

Health and Safety educators are stalwarts in fight for social justice and believe that the health and safety of a population should be a priority in any society.

Health and Safety as an integral part of educational system deals with the avoidance of health and property hazards, risks, the promotion of adequate and quality wellbeing of individuals, the control of environmental influences which pose threat to both human and properties. Health and safety educational management begins with people and geared towards improving the living conditions of the people and to 
develop in them a sense of responsibility for health conditions for themselves as individuals, as members of families and as communities. It involves the appraisal and assessment of health and safety habits, attitudes and skills of the people as they relate to spread and frequency of diseases and hazards around them. It is the family, society and the school that determines the environmental situations which influences health habits and safety attitudes of and individuals, community and society.

Thus, Health and safety educational management as one of the facet of the school health programs and the total school curriculum is integral to "Education for All". Good health is essential for effective learning as well as safety in maintaining healthy learning environment, free from hazardous influences and education is a powerful tool inculcating in children and adults ways to attain and maintain good health and recognition of health and environmental hazards. Not only does health and safety education have a direct impact on the school pupils but through the pupils' examples can benefit families, communities and the entire society.

According to UNESCO/UNDP (1995), Topic II, it states that the focus of Health and safety Education is on.

- The important behaviours and condition that promote health and those that put health at risk.

- Acquisition of skills needed to practice those positive behaviours and address those risky behaviours and hazardous condition by personally and collectively.

- Imparting knowledge, attitude, beliefs, and values related to those behaviours and conditions.

- Providing learning experiences that allows students to model and practice those skills.

\section{Principles of Health Education}

i. It is a process whereby people learn to improve their personal habits and attitudes to work responsibly for the improvement of health conditions of the family, community and nation.

ii. It considers the health status of the people which is determined by the economic and social conscience of the country.

iii. It involves motivation, experience and exchange in conduct and thinking while stimulating active interest. It develops and provides experience for change in people's attitudes, customs and habits in relation to health and every day living.

iv. Utilize all educational opportunities for health; formal and informal, traditional and alternative, inside and outside school.

v. Empower students to act for health living and to promote conditions supportive of health.

vi. Establish a life long learning of health issues.

vii. It aims to help people make use of their own effects and education to improve their living conditions.

viii. It makes careful evaluation of the planning, organization and implement of all health education program and activities.

ix. It is a cooperative activity requiring all categories of health personnel to work together in close team work with families, groups and the community.

$x$. It meets the needs, interests and problem of people affected.

\section{Principles of Safety Education}

1. Involve young people in real decision making to help them stay safe this includes young people's participations in real decisions about keeping themselves safe in and out of classroom. Activities for young people should include identification of hazards, participating in risk assessment (e.g. assessing whether risks are trivial, tolerable or intolerable) and being part of actions to control or manage risks to themselves and others. 
2. Teach safety as part of a comprehensive personal, social and health curriculum - A curriculum helps children and young people learn how to keep themselves healthy and to stay safe. It provides opportunities to learn specific and transferable skills and knowledge in a wide range of circumstances but with attention to feelings, skills, attitudes, values and attributes.

3. Use realistic and relevant setting and resources in Safety Education - Real life data and example (but not those designed simply to shock) help to engage young people and to challenge misconceptions e.g. bully is an acceptable behaviour among children, or accidents just happen where necessary. (Using data in this way is also known as normative approach).

4. Address known risks and protective factor - Risks and protective factors can be anything that is associated with greater or lesser probability of a child or young person experiencing harm. Risks are not static and can be divided into domains: Individual (e.g. knowledge and skill) school (e.g. Policy) Peer groups (e.g. attitudes).

5. Family (e.g. parental rules) and community (e.g. Crimes). An understanding of risks and protective factors can help those designing and delivering safety education resources to focus on wide aspects of injury prevention and personal safety.

6. Address psychological aspect of safety e.g. confidence, resilience, self esteem and efficacy psychological risks and protective factors are individual characteristics that may predispose children to injury, or to being a victim of bullying, violence or abuse. Psychological aspects of behaviour operate dynamically with environmental factors, reinforcing the importance of incorporating individual protective factors (such as confidence, resilience, self esteem and self efficacy) within a whole community approach.

7. Adopt positive approaches which model and reward safe behaviour, within a safe, supportive environment - It is helpful to identify the short and long term benefits of maintaining safe and healthy behaviour that is harmful to health. Children and adults learn from observing and modeling the behaviour of others, including peers and generalize their expectation of positive outcomes across different domains.

8. Work in partnership - Develop links with supporting agencies such as policy, fire, rescue, local authorities and educational charities where these add value to work carried out in schools and other setting. Work with parents and members of wider community by seeking their views, providing information, guidance and involving them in developing and implementing solutions and ensures healthy learning surroundings free from environmental hazards.

Health and safety educational management provides educational programs, resources and services to foster students' Organizational Culture that thinks proactively about personal safety and wellbeing at home, at school - during co-curricular activities and how to manage potential risks.

In safety education, there is shared responsibility for the safety of both students and staff. Each person must acknowledge the critical role in ensuring his own safety and that of others. Both students and staff are provided with resources and tools they can use to plan safe events and activities as well as risk management and prevention.

\section{Importance of health and Safety Education}

Knowledge of health and Safety is vital as it concerns the acquisition of safety skills, habits and health attitudes for the effective functioning of the body, maintenance of healthy environment free from dangers or hazards for the promotion of quality health of the society.

1. It builds students' knowledge, skills and positive attitudes about health and risks needed to be avoided.

2. It motivates students to improve and maintain their health, prevent disease and reduce risky behaviours. 
3. Students learn skills they will use to make healthy choices throughout their life time.

4. It results in positive change in behaviour that lower students' risks associated with.

5. Use of alcohol, tobacco and other drugs.

6. Sustenance of injury.

7. Mental and emotional instability.

8. Nutrition.

9. Physical activity.

10. Sexuality and family life etc.

Health and Safety Educational management helps to mitigate risks in any given situation, hence knowledge of health and safety is important in

Helping facilities (schools, hospitals, industries etc) to be competent in delivering proficient and safe care practices while maintaining a protected environment from potential harm in an economy of a given nation.

Studies have shown that students whose behaviours/ attitudes have been modified as a result of health and safety sequel to the instructions and trainings tend to do better in school. Their attendance, grades and performance during assessment were significantly higher than those that have not

\section{Scope of Health and Safety Educational Management}

Health and safety educational is a very vast term and has a very wide scope. It is dependent and closely related to many other aspects besides health and safety. Those aspects include housing, economic security, agricultural or industrial prosperity etc. Ordinarily health education includes the following:

1. Food and its importance in the development of human body. It touches all branches of human life namely personal life, school life and community life.

2. Water, air, light, physical exercises, recreation, rest, sleep etc.

3. Abnormal conditions and bad habits. Their adverse effect on the physical and mental health of an individual.

4. Various ailments and diseases. Their causes, ways and means of their prevention and cure.

5. Mental health, sex, hygiene, domestic and community hygiene.

6. Emergency and first aid.

7. Misuse of alcohol, drug and tobacco and harm reduction.

8. Effective stress management.

9. Cultivating and sustaining healthy relationships.

10. Coping with test anxiety, improving time management and sexual health promotion.

11. Safety Education and first aid

\section{Scope of Safety Education}

i. Hazards control.

ii. Fire protection.

iii. Ergonomics.

iv. Process and system safety.

v. Safety and health management.

vi. Job hazard analysis.

vii. Accident investigation and analysis.

viii. Product safety.

ix. Construction safety.

$x$. Education and training methods. 
xi. Measurement of safety and health.

xii. Human behaviour.

xiii. Environmental safety and health regulations and standards.

xiv. Health and environmental laws etc.

$x v$. First aid.

\section{Recommendations}

1. Health and safety educational management curriculum should be formulated and implemented in schools so as to develop in students an objective and positive thinking towards health and safety principles and practices.

2. It is evident that people lack proper training in health and safety practices which usually results to fatality; hence it should be adequately looked upon.

3. Workers engage in unsafe and hazardous practices which are due to lack of regular induction and pep talk regarding healthy and safety measures at their work places adequate protective measure should be adhered to.

4. The management staffs need to put in place health and safety committees whose duties are to conduct pep talks, induct workers and students regularly and analyze hazards in the environment and during construction and maintenance of dilapidated school structures this committee should make sure that the contractor make available safety materials such as personal protective equipments (PPEs) for site workers to avoid unnecessary accidents.

5. Management should organize seminars regularly on health and safety and involve both staffs and students so that they can see the need to engage in safe practices and live and maintain quality health in order to be beneficial to both self and the society at large.

\section{References}

Ajibola, A.C (2008). Safety and Health - A proactive approach. Macson Publishers Emene, Enugu State.

Akwue, P. (2011) Health Safety and Environmental Technology. (HSE). Downtown Publishers Warri, Delta State.

Downie et al (1996). Health Education policies and principles. Climax Publishers, London.

Green and kreuter (2005) Health and You - Building a Healthy Society. Clinton Publishers Texas, USA.

Okoye (1999). Health Education Policies. Prince Publishers Nnewi, Anambra State.

Orji C.M (1994). Risk Management and Analysis. Emans Publishers Abakpa, Enugu State.

The Joint Committee on Health Education and Promotion Terminology (2011).

UNESCO / UNDP (1995). Topic 11, Health and Safety Practices. 
